\section{Response of patent medicine vendors in rural areas of Lagos state Nigeria to antimalarial policy change}

Abisoye Oyeyemi ${ }^{1}$, Babatunde Ogunnowo ${ }^{2}$, Oluwakemi Odukoya ${ }^{2}$

1. Department of Community Medicine, Faculty of Clinical Sciences, College of Health Sciences, Niger Delta University, Wilberforce Island, Bayelsa State, Nigeria.

2. Department of Community Health and Primary Care, College of Medicine, University of Lagos, Idi-Araba, Lagos, Nigeria.

\section{Abstract:}

Background: Patent medicine vendors (PMVs) play an important role in the treatment of malaria, especially in the rural areas. Nigeria recently changed her antimalarial treatment policy from chloroquine to artemisinin-based combination therapy (ACT).

Objectives: To determine the response of PMVs to the new policy.

Methods: A baseline study was conducted in two local government areas (LGAs) of Lagos state Nigeria as the first phase in an intervention study aimed at improving the malarial treatment practices of PMVs in rural Lagos. A mixed method design involving a questionnaire survey of 180 PMVs and four key informant interviews were used. An antimalarial drug (AMD) audit was also performed.

Results: More than $80 \%$ of respondents were aware of the policy change in malaria treatment, but only $23.9 \%$ sold an ACT for the last case of malaria treated in an under five child. The main determining factor of the particular AMD sold was PMV's personal choice $(70.6 \%)$. About half $(58.9 \%)$ of the shops stocked ACTs, the newly recommended antimalarials Conclusions: The high awareness of the policy change did not translate to a commensurate increase in the sale of the new Conclusions: The high awareness of the policy change did not translate to a commensurate increase in
drugs. Factors beyond the PMVs need to be addressed for a successful adoption of the new policy.

Key words: Patent Medicine Vendors, ACTs, policy change, malaria, artemisinin monotherapies, non-artemisinin therapie DOI: http://dx.doi.org/10.4314/ahs.v15i2.15

\section{Introduction}

Malaria remains a leading cause of morbidity and mortality in Nigeria as in other sub-Saharan Africa countries. ${ }^{1}$ Appropriate treatment of uncomplicated malaria currently means the use of artemisinin-based combination therapies (ACTs) as recommended by World Health Organization (WHO). ${ }^{2}$ Nigeria adopted ACTs as the drugs of choice for the management of uncomplicated malaria in 2004 following drug therapeutic efficacy trials which confirmed widespread resistance to the

\section{Corresponding author:}

Abisoye Oyeyemi

Department of Community Medicine,

Faculty of Clinical Sciences, College

of Health Sciences, Niger Delta University,

Wilberforce Island, Bayelsa State, Nigeria.

Tel: +2348037049837,

E-mail: abisoyeyemi@hotmail.com erstwhile drugs of choice and demonstrated adequate response to selected ACTs. ${ }^{3}$ Artemether-Lumefantrine aquine $(\mathrm{AA})$ is the alternate treatment.

Patent Medicine Vendors (PMVs) are important informal community-based providers of health care, who by law are permitted to sell only patent (nonprescription) medicines in their original prepackaged forms. ${ }^{4}$ sell drugs by simply filling prescriptions, prescribe and then sell, instruct/advise clients on the use of drugs sold, and refer clients to formal health facilities.- ${ }^{7-9}$ Many countries, in their bids to ensure equitable access of the population to essential drugs, permit PMVs to sel over-the-counter (OTC) drugs, including antimalarials drugs (AMDs). ${ }^{10,11}$ Studies across Africa have shown that between $15 \%$ and $82 \%$ of recent childhood illnesses (most of which are malaria) are managed by PMVs as the first provider of care ${ }^{5,6,12,13}$ This is supported by recent studies in Nigeria ${ }^{14,15}$ including the Nigeria malaria indicator survey $(2010)^{16}$ which reported that $57.4 \%$ of with fever used PMVs as the firs treatment point. The burden of malaria is known to be (AL) is the preferred ACT, while Artesunate-AmodiThey operate in both urban and rural areas where they heavier in the rural areas ${ }^{15,17}$ and it was estimated that $58 \%$ of malaria deaths occur in the poorest $20 \%$ of the world's population, most of who reside in the rural areas. ${ }^{18}$

Studies have shown that despite change in antimalaria drug policy, both providers and consumers continued to use the erstwhile drugs for a long time for various reasons. ${ }^{19-22}$ This slow adoption is not without consequences as the problems that necessitated the change remain.

PMVs' shops belong to Level 1 in the three-level hierarchy of disease management facilities in Nigeria. Others at this level are primary health care centres, dispensaries and health posts. ${ }^{3}$ The PMVs are permitted to treat uncomplicated malaria with ACTs in the new policy. ${ }^{3}$ This study aimed to assess the response of the dominant providers of AMDs in the rural areas after about five years of change in the antimalarial treatment policy.

\section{Methods}

Study setting

The study was conducted in Lagos State, which is one of the 36 states of the Federal Republic of Nigeria. It is located in the southwestern zone and had an estimated population of 10,016,807 for 2009 as projected from the 2006 census. ${ }^{23}$ It is divided into 20 Local Government Areas (LGAs); 16 are classified as urban and four as rural. The rural LGAs are Ikorodu, Epe, Ibeju-Lekki and Badagry. ${ }^{24}$ The study was carried out in Ikorodu and Ibeju-lekki LGAs.

There were two independent umbrella associations for PMVs in Lagos state: Lagos State Medicine Dealers' Association (LSMDA) and National Association of Patent and Proprietary Medicine Dealers (NAPPMED). The authors first established contact with LSMDA; it was much later while pre-testing the data collection instruments that the parallel association was discovered. A decision was made to limit the study to LSMDA to avoid the complexity of involving the two bodies. LSMDA had a branch in each LGA and for ease of administration; it subdivided its large LGAs into zones.

Ikorodu had an estimated population of 580,236 for $2009 .{ }^{23}$ The Ikorodu branch of the Lagos State Medicine Dealers Association (LSMDA) had 482 registered PMVs in its four zones and they were distributed thus: Ikorodu South (82), Ikorodu Central (75), Odogunyan (184) and Igbogbo (141). Ibeju-Lekki is another ru-
LGA in the state with an estimated population of had 157 registered PMVs operating in the LGA.

\section{Study design}

This report is from the pre-intervention phase of an intervention study designed to improve the malarial treatment practices of PMVs operating in rural Lagos. A mixed method design was used and it involved a questionnaire survey and key informant interviews. The study population comprised only LSMDA-registered PMVs operating in Ikorodu and in Ibeju-Lekki LGAs of Lagos state. Where the shop owner was not the one actively involved in operating a selected shop, the person in charge, either an apprentice or a sales attendant who usually sold drugs to clients was interviewed.

\section{Sample size estimation}

The minimum sample size for the intervention study was estimated using the formula for comparison of two proportions. ${ }^{25}$ A study conducted in Oyo state, which is in the same geopolitical zone with Lagos found that $79.5 \%$ of PMVs were aware of the new policy. ${ }^{26}$ We expected our intervention to raise the awareness to at least $95 \%$. At alpha of $5 \%$ and power of $80 \%$, and allowing for attrition and uncompleted interviews, $20 \%$ of the size calculated was added and rounded up to 90 .

\section{Sampling methodology}

Ikorodu and Ibeju-Lekki LGAs were randomly selected (by balloting) out of the four rural LGAs in the state. In Ikorodu, for methodological and logistical reasons, Odogunyan zone was purposively selected out of the four zones in the LGA but the respondents were randomly selected using a table of random numbers. The table of random numbers was also used to select the respondents in Ibeju-Lekki. A list of all registered PMVs in each study location constituted the sampling frame.

\section{Data collectio}

Data collection, which took place in July /September 2009, was done using a pretested structured interviewer-administered questionnaire, key informant interview guide and an observational checklist. One hundred and eighty PMVs (90 in each LGA) were interviewed and their shops were observed. One of the authors and two trained research assistants administered the instruments. The questionnaire elicited information on the socio-demographic characteristics of the PMVs, their knowledge of the new policy on malaria treatment and 
their treatment practice. As an indicator of the current to determine predictors of ACT sale. A p-value $<0.05$ treatment practice, the PMVs were asked to mention was considered statistically significant. The key informthe AMD sold for the last case of malaria treated in ant interviews were tape-recorded, transcribed and oran under-five child. Drug audit was performed using a ganized under thematic headings. Content analysis ${ }^{28}$ was checklist. All the AMDs in stock for sale were identified. employed to identify responses and findings were preOne of each type of the drugs was arbitrarily selected sented under major themes. The main outcome measby the interviewer and checked for NAFDAC number ures were awareness of the policy change, stocking and and expiry date. The presence of NAFDAC number is sale of the recommended ACTs.

an indication that the product is duly registered. The chairperson and the secretary of the association in each grood knowledge of the subject matter and be able add depth to the interview.

\section{Data analysis}

The Epi Info 2002 (Windows version 3.5.1) was used included consent for te for data entry, cleaning, and analysis. The drugs with ant interview.

their different proprietary names were classified into the following broad generic groups: ACTs, artemisinin monotherapies (AMTs), and non-artemisinin thera- Results pies (NATs). The ACTs were further classified into Sociodemographic characteristics

those containing artemether-lumefantrine (AL), ar- Table 1 shows that most of the respondents $(148 / 82.2 \%)$ tesunate-amodiaquine $(\mathrm{AA})$ and others. Chi-square test were shop owners and their ages ranged from 16 to (with Yates correction in $2 \times 2$ tables) and Fisher's exact 67 years. More than $90 \%$ had secondary education and test were done to find association between categorical $31.7 \%$ had health training background, mainly auxiliavariables. Multiple logistic regression analysis was done ry nursing. Statistically significant differences exist between the two LGAs in some characteristics. nowledge of current malaria treatment policy Majority of the PMVs $(150 / 83.3 \%)$ reported bein aware of change in the malaria treatment policy but further questions to establish their knowledge of relevant components as it affects their practice showed only 10 $(5.6 \%)$ had good knowledge, edge and $96(53.3 \%)$ had poor knowledge of the policy.

Sale of antimalarials and reasons for the sale
About a quarter $(43 / 23.9 \%)$ of respondents sold an ACT for the last case of malaria treated in an under-five the most frequently sold AMDs (100/55.6\%) (Figure 1). Figure 2 shows that $14 / 32.6 \%$ of the ACTs sold were AL while $27 / 62.8 \%$ were AA combination. In (27/70.6\% of AMD sales, the PMV made the choice (Figure 3). A further analysis of the three determinants of drug sale shows that NATs were the most frequently sold AMD by PMVs $(67 / 52.8 \%)$ and also the most

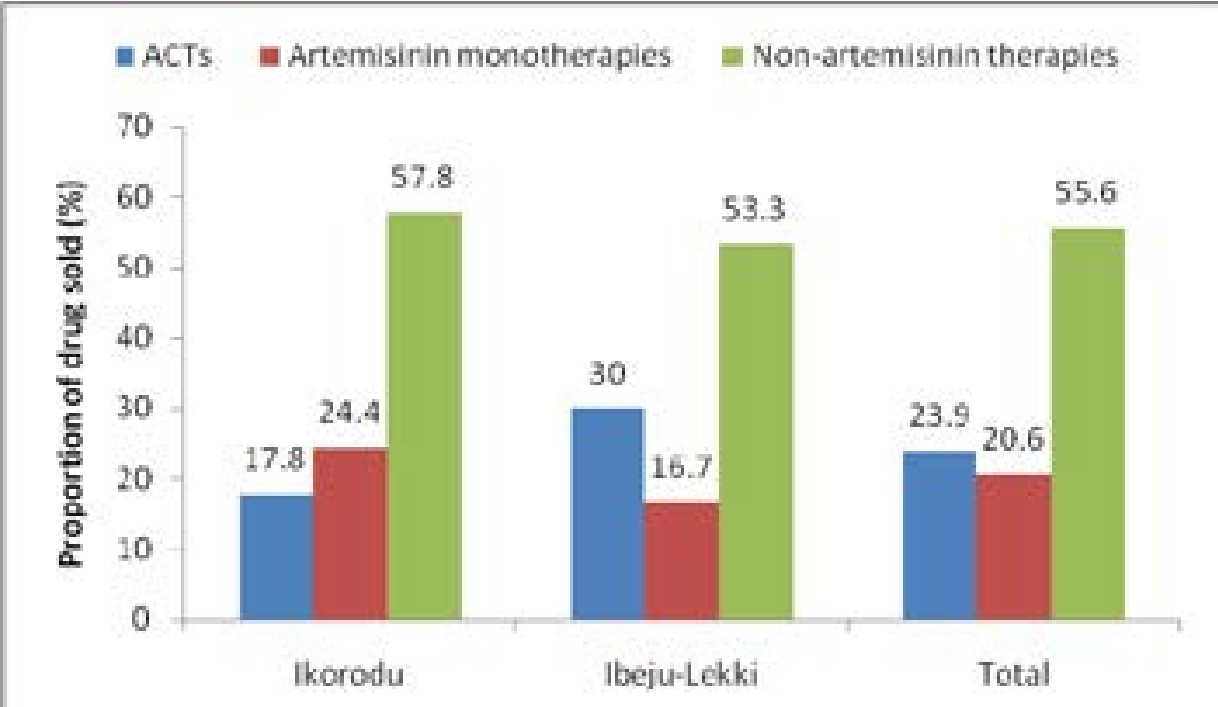

Figure 1: Antimalarial drug sold for the last under-five child treated for malaria

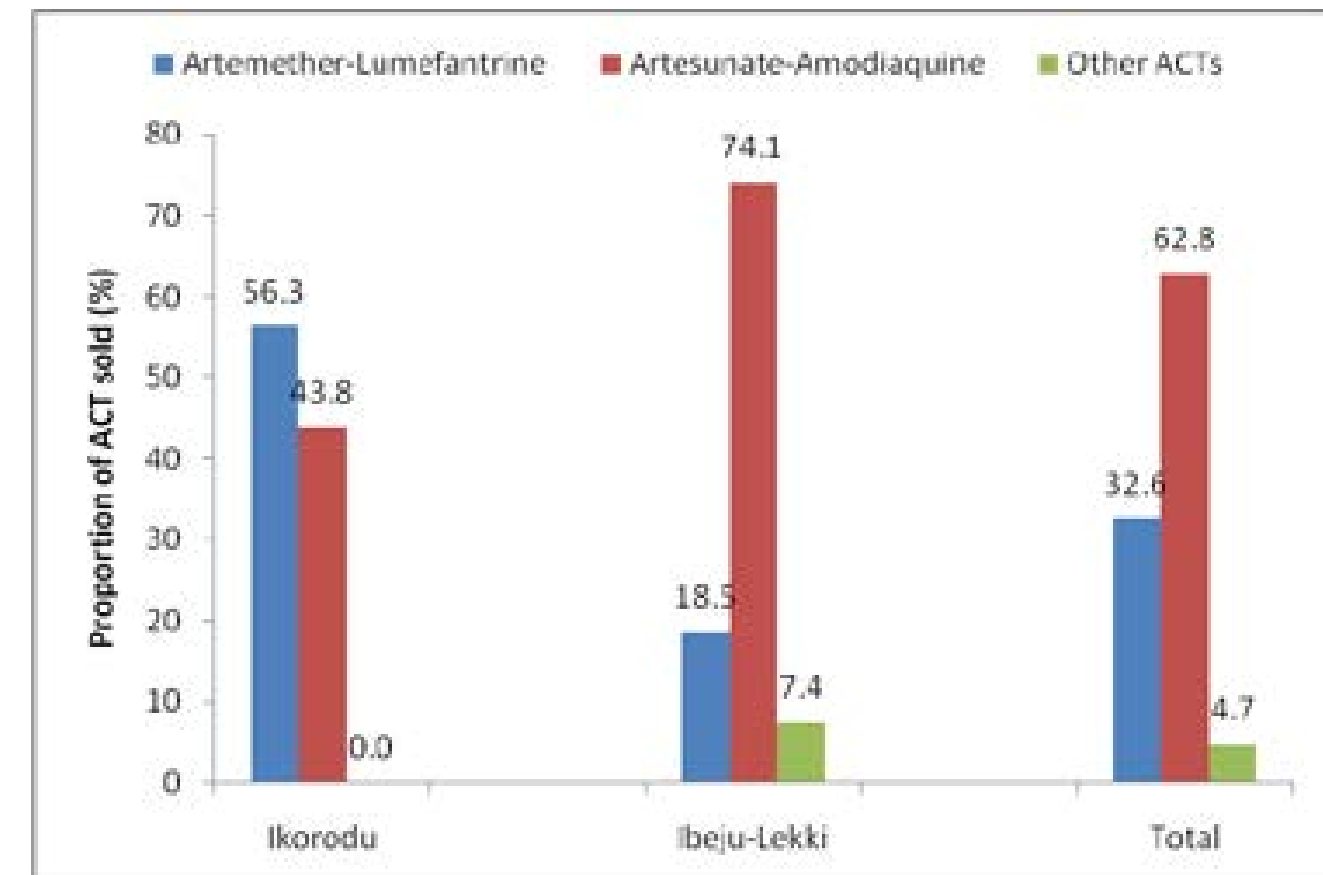

Figure 2: Types of ACT sold for the last under-five child treated with an ACT

\begin{tabular}{|c|c|c|c|c|c|}
\hline Characteristic & \begin{tabular}{|l|} 
Ikorodu \\
(n=90) \\
Freq (\%)
\end{tabular} & $\begin{array}{l}\text { Ibeju-Lekki } \\
\text { (n-90) } \\
\text { Freq }(\%)\end{array}$ & \begin{tabular}{|l|l|} 
Total \\
(n=180) \\
Freq $(\%)$
\end{tabular} & $x^{2}$ & p-value \\
\hline $\begin{array}{l}\text { Respondent } \\
\text { Shop owner } \\
\text { Sales attendant } \\
\text { Apprentice }\end{array}$ & $\begin{array}{c}78(86.7) \\
6(6.7) \\
6(6.7)\end{array}$ & $\begin{array}{l}70(77.8) \\
55(5.6) \\
15(16.7)\end{array}$ & $\begin{array}{r}148(82.2) \\
11(6.1) \\
21(11.7)\end{array}$ & 4.38 & 0.112 \\
\hline $\begin{array}{l}\text { Age group (yrs) } \\
<21 \\
211-29 \\
30-39 \\
\geq 40 \\
\text { Mean age }\end{array}$ & $\begin{array}{c}2(2.2) \\
32(35.6) \\
43(47.8) \\
13(14.4) \\
32.2 \pm 7.4\end{array}$ & $\begin{array}{c}8(8.9) \\
40(44.4) \\
35(38.9) \\
7(7.7) \\
29.6 \pm 7.9\end{array}$ & $\begin{array}{l}10(5.6) \\
72(40.0) \\
78(43.3) \\
20(11.1) \\
30.9 \pm 7.8\end{array}$ & 7.11 & 0.068 \\
\hline $\begin{array}{l}\text { lex } \\
\text { Female } \\
\text { Male }\end{array}$ & $\begin{array}{l}58(64.4) \\
32(35.6)\end{array}$ & $\begin{array}{l}37(41.1) \\
53(58.9)\end{array}$ & $\begin{array}{l}95(52.8) \\
85(47.2)\end{array}$ & 8.92 & 0.003 \\
\hline $\begin{array}{l}\text { Education } \\
\text { Primary } \\
\text { Secondary } \\
\text { Tertiary }\end{array}$ & $\begin{aligned} & 7(7.8) \\
& 70(77.8) \\
& 13(14.4)\end{aligned}$ & $\begin{array}{r}9(10.0) \\
74(82.2) \\
7(7.8)\end{array}$ & $\begin{array}{r}16(8.9) \\
144(80.0) \\
20(11.1)\end{array}$ & 2.16 & 0.339 \\
\hline $\begin{array}{l}\text { Marital status } \\
\text { Married } \\
\text { Single }\end{array}$ & $\begin{array}{l}68(75.6) \\
22(24.4)\end{array}$ & $\begin{array}{l}39(43.3) \\
51(56.7)\end{array}$ & $\begin{array}{r}107(59.4) \\
73(40.6)\end{array}$ & 19.38 & $<0.001$ \\
\hline $\begin{array}{l}\text { Ethnic group } \\
\text { Igbo } \\
\text { Yoruba } \\
\text { Others }\end{array}$ & $\begin{array}{l}30(33.3) \\
39(43.3) \\
21(23.3)\end{array}$ & $\begin{array}{c}55(61.1) \\
30(33.3) \\
5(5.6)\end{array}$ & $\begin{array}{l}85(47.2) \\
69(38.3) \\
26(14.5)\end{array}$ & 18.37 & $<0.001$ \\
\hline $\begin{array}{l}\text { Religion } \\
\text { Christianity } \\
\text { Islam }\end{array}$ & $\begin{array}{l}76(84.4) \\
14(15.6)\end{array}$ & $\begin{array}{l}80(88.9) \\
10(11.1)\end{array}$ & $\begin{array}{r}156(86.7) \\
24(13.3)\end{array}$ & 0.43 & 0.511 \\
\hline
\end{tabular}




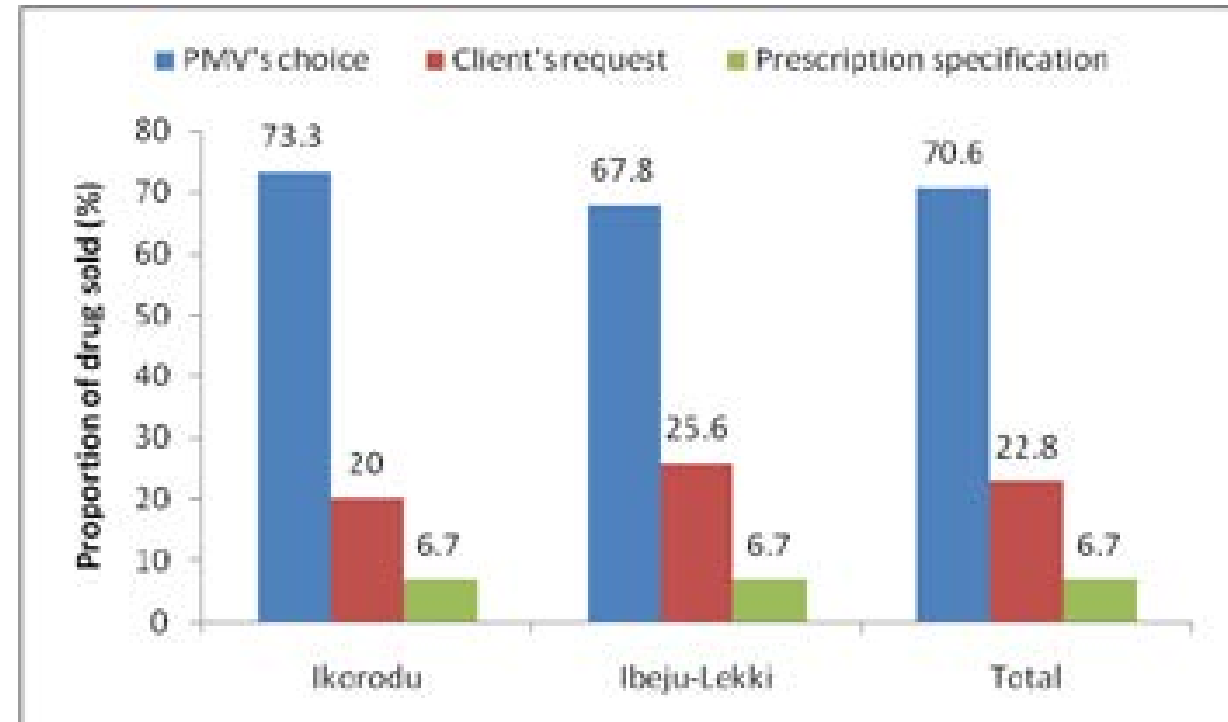

Figure 3: Determinant of antimalarial drug sold for the last under-five child treated for malaria

Table 2: Analysis of drug sold by the three determinants of sale

\begin{tabular}{|c|c|c|c|c|c|}
\hline Antimalarial & $\begin{array}{l}\text { Ikorodu } \\
\text { Freq (\%) }\end{array}$ & $\begin{array}{l}\text { Ibeju-Lekki } \\
\text { Freq (\%) } \\
\end{array}$ & $\begin{array}{l}\text { Total } \\
\text { Freq (\%) } \\
\end{array}$ & $\chi^{2}$ & 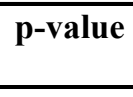 \\
\hline \multicolumn{6}{|c|}{ Drug sale by PMV's choice } \\
\hline ACTs & $12(18.2)$ & $23(37.7)$ & $35(27.6)$ & 7.24 & 0.027 \\
\hline $\begin{array}{l}\text { Artemisinin } \\
\text { monotherapies }\end{array}$ & $17(25.8)$ & $8(13.1)$ & $25(19.7)$ & & \\
\hline $\begin{array}{l}\text { Non-artemisinin } \\
\text { therapies }\end{array}$ & $37(56.1)$ & $30(49.2)$ & $67(52.8)$ & & \\
\hline Total & $66(100.0)$ & $61(100.0)$ & $127(100.0)$ & & \\
\hline \multicolumn{6}{|c|}{ Drug sale by client's specific demand } \\
\hline ACTs & $1(5.6)$ & $2(8.7)$ & $3(7.3)$ & & $0.648^{*}$ \\
\hline $\begin{array}{l}\text { Artemisinin } \\
\text { monotherapies }\end{array}$ & $2(11.1)$ & $5(21.7)$ & $7(17.1)$ & & \\
\hline $\begin{array}{l}\text { Non-artemisinin } \\
\text { therapies }\end{array}$ & $15(83.3)$ & $16(69.6)$ & $31(75.6)$ & & \\
\hline Total & $18(100.0)$ & $23(100.0)$ & $41(100.0)$ & & \\
\hline \multicolumn{6}{|c|}{ Drug sale by prescription specification } \\
\hline ACTs & $2(33.3)$ & $3(50.0)$ & $5(41.7)$ & & $0.567^{*}$ \\
\hline $\begin{array}{l}\text { Artemisinin } \\
\text { monotherapy }\end{array}$ & $2(33.3)$ & $3(50.0)$ & $5(41.7)$ & & \\
\hline $\begin{array}{l}\text { Non-artemisinin } \\
\text { therapy }\end{array}$ & $2(33.3)$ & 0 & $2(16.7)$ & & \\
\hline Total & $6(100.0)$ & $6(100.0)$ & $12(100.0)$ & & \\
\hline
\end{tabular}

*Fisher exact p-value

frequently demanded by clients $(31 / 75.6 \%$ ) (Table 2$) . \quad$ in $58.9 \%$ of the shops but a significant difference exists Antimalarial drug audit Table 3 shows the various types of AMDs found in the ly chloroquine $(92.8 \%)$ and sulphadoxine-pyrimethdrug shops. All the antimalarials examined had NAF- amine (87.8\%) dominated the shops followed by AMTs DAC number and none had expired. ACTs were found $\quad(75.6 \%)$.

Table 3: Antimalarial drugs found in the observed patent medicine shops

\begin{tabular}{llllll}
\hline Antimalaria & $\begin{array}{l}\text { Ikorodu } \\
\text { n=90 } \\
\text { Freq (\%) }\end{array}$ & $\begin{array}{l}\text { Ibeju-Lekki } \\
\mathbf{n = 9 0} \\
\text { Freq (\%) }\end{array}$ & $\begin{array}{l}\text { Total } \\
\text { N=180 } \\
\text { Freq (\%) }\end{array}$ & $\chi^{\mathbf{2}}$ & p-value \\
& & & & & \\
CQ & $80(88.9)$ & $87(96.7)$ & $167(92.8)$ & 2.98 & 0.084 \\
SP & $81(90.0)$ & $77(85.6)$ & $158(87.8)$ & 0.47 & 0.495 \\
AMTs & $66(73.3)$ & $70(77.8)$ & $136(75.6)$ & 0.27 & 0.603 \\
ACTs & $39(43.3)$ & $67(74.4)$ & $106(58.9)$ & 16.73 & $<0.001$ \\
Amodiaquine & $17(18.9)$ & $10(11.1)$ & $27(15.0)$ & 1.57 & 0.210 \\
Pyrimethamine & $33(3.3)$ & $10.11 .1)$ & $13(7.2)$ & 2.98 & 0.084 \\
Halofantrine & $2(2.2)$ & $10(11.1)$ & $12(6.7)$ & 4.38 & 0.036 \\
Quinine & $4(4.4)$ & $7(7.8)$ & $11(6.1)$ & 0.39 & 0.534 \\
Others & $0(0.0)$ & $3(3.3)$ & $3(1.7)$ & & $0.246^{*}$ \\
\hline
\end{tabular}

*Fisher exact p-value

\section{Predictors of ACT sale by PMVs}

Multiple logistic regression analysis was done to identify predictors of ACT sale among PMVs who made the choice of AMD for their clients. Independent variables in the model were respondent status, education, previous health-related training, previous $\mathrm{CPD}$ on malaria, years of practice, and awareness of change in the treatment policy. None of the factors was predictive of ACT sale.

\section{Key informant interview}

Knowledge of the current antimalarial treatmen policy

The four officials interviewed were aware of change in the policy but none of them knew the year the new guidelines came into effect.

New drugs for treating malaria: All said ACTs are now the recommended drug for treating malaria in children and adults. A chairperson explained, "Chloroquine is so abused and is no longer effective. Combination is needed now, AL or AA". A secretary said, "we were told in Eko FM seminar that chloroquine and fansidar (an SP) are no longer active, that ACTs are the active ones." Availability and affordability of the new drugs: they all agreed that the drugs were available but the prices were high compared with CQ and SP. A chairperson said, "... the prices of the new drugs are on the high side. For example fansidar is $\mathrm{N} 130$ - N150 (\$0.93 - \$1), Amatem (a brand of $\mathrm{AL}$ ) is N500 (\$3.8), not in favour of the poor masses." Another chairperson added, "initially so expensive, we don't stock them. SFH (Society for Family Health) came in and subsidized just for children. They supply only those who attended the seminar they organized." The drugs according to them were widely acceptable to buyers, only that many still could not afford them. Ikorodu secretary said, "they rely on what we tell them and they are convinced."

\section{Discussion}

This study examined the response of PMVs in rural Lagos regarding malaria treatment about five years after change in policy from chloroquine to ACTs for the treatment of uncomplicated malaria. The erstwhile first-line and second-line non-artemisinin therapies NATs), i.e., chloroquine (CQ) and sulphadoxine-pyrimethamine (SP) respectively, were still the most commonly sold AMDs for the treatment of uncomplicated malaria in under-five children, a finding which is at varance with the new policy recommendation. The sale mirrors the stock of AMDs found on drug audit, which showed that CQ and SP still had dominion of the market. These findings are in consonance with other studies in Nigeria ${ }^{21,26,27}$ and elsewhere ${ }^{19,22}$ where, despite change in treatment policy, formerly used AMDs were still on 
sale in drug shops even years after the change. The wide availability and sale of CQ and SP implies that many cases of uncomplicated malaria were still receiving inappropriate treatment with consequences including progression to severe illness, increased mortality and growing drug resistance.

Artemisinin monotherapies (AMTs) were the second most common group of antimalarials in stock while ACTs were the third with a significant difference between the two LGAs. Regarding sale, overall, ACTs came a distant second to the NATs in the type of AMDs sold but the pattern of sale was different in the two LGAs. The type of ACT sold also varies in the two LGAs and even though AL is the first line ACT, overall AA was the highest in sale volume. Both $\mathrm{AA}$ and $\mathrm{AL}$ are taken over three days but while $\mathrm{AA}$ is taken once daily, $\mathrm{AL}$ with a somewhat complex dosage regimen and more pills/syrup to swallow is taken twice daily. This may make AA more appealing to both the user (who would prefer a light drug burden) and the drug seller (who would have to explain how to use the drug). The differential ACT penetration and sale in the two LGAs shows that even in supposedly similar settings (both rural areas) diverse factors might be at play, including differences in drug supply chain and preferences of clients.

The continued presence of AMTs in the shops is worrisome. Suspected resistance to artemisinins has been identified ${ }^{29}$ and there is growing concern that this may spread if AMTs continue to be used. WHO has recommended their withdrawal and replacement with ACTs but they are still widely on sale in many countries, most of which are in Africa. ${ }^{29}$ The Pharmacists Council of Nigeria (PCN), which is the government regulatory agency that monitors the practice of $\mathrm{PMVs}^{30}$ has not revised the approved list of antimalarials PMVs are allowed to sell ${ }^{31}$ to reflect the policy recommendation as at the time of this study. The continued presence of the previously recommended drugs on the approved list may thereby create confusion and weaken adoption of the new policy. In addition, the availability of non-approved AMDs in many shops is a pointer to weak regulation, enforcement and monitoring of the practice of the PMVs by PCN

In this study, three factors determined malaria treatment options. First, many clients simply approached the medicine sellers without any predetermined drug and the choice was left to the PMVs. Second, some uyers asked for a particular drug, and third a few came with a prescription. Just like a typical patient in a hospital leaves treatment decision for the clinician, more than $70 \%$ of the clients considered the PMV as the doctor whom they believed knew what was best for them. That only $27.6 \%$ of these PMVs sold ACTs despite more than $80 \%$ of them being aware of the change suggest that factors beyond their knowledge played a significan role. None of the hypothesized provider factors was predictive of ACT sale by the PMVs. The officers of the PMVs' association stated that many people could not afford the ACTs, though the drugs were acceptable to the communities. The PMVs seemed to respond to this by simply offering what they knew the people could afford i.e., CQ and SP. This was similar to the experience of PMVs in the in-depth study in Enugu Nigeria. ${ }^{32}$ All the respondents said they had heard of artemisinin derivatives but none had it in their shops. One of them captured their reason thus, "we cannot stock because of the high cost. If you do, no villager will buy it from you because they are very poor.'

Majority of the clients who bought AMD from the PMVs specifically demanded NATs. This suggests low level of awareness of the new drugs by the caregivers. Community based studies revealed poor awarenes of ACTs among households. ${ }^{15,21}$ This underscores the need for consumer education about the new treatment policy.

\section{Limitations of the study}

Odogunyan zone in Ikorodu LGA was purposively selected out of the four zones and might theoretically not be representative of the entire LGA. NAPPMED members were not involved in the study. This limits generalization of the findings to all vendors operating in the rural areas of Lagos state. Since information about the indicator of drug sale was retrospectively collected, recall bias cannot be completely ruled out.

\section{Conclusion}

Five years after change in antimalarial treatment policy, the high awareness among PMVs was yet to translate to a commensurate increase in the sale of the new drugs (ACTs). NATs and AMTs continued to dominate the market with dire consequences for malaria control. Factors beyond the PMVs like clients' knowledge of the policy change, exorbitant prices of the ACTs and continued availability of older antimalarial drugs in the market need to be addressed in order to optimize the use of ACTs. The authors recommend that the government should implement sustainable initiatives that will make ACTs more affordable to the people; government and other stakeholders in malaria control should enlighten the citizenry on the new drugs and discourage demand and use of drugs that are no longer effective; the PCN should without further delay revise the approved list of antimalarial drugs PMVs are allowed to sell; and government should initiate effort to withdraw non-ACT antimalarials from the mar-

\section{References}

1. Federal Ministry of Health, National Malaria and Vector Control Division, Abuja-Nigeria. National Antimalarial Treatment Policy. February 2005.

2. World Health Organization. WHO Guidelines for the treatment of Malaria Switzerland: World Health Organization; 2006.

3. Federal Ministry of Health, National Malaria and Vector Control Division, Abuja-Nigeria. National Antimalarial Treatment Policy. February 2005.

4. Goodman C, Brieger W, Unwin A, Mills A, Meek

S, Greer G. Medicine sellers and malaria treatment in Sub-Saharan Africa: what do they do and how can their practice be improved. Am J Trop Med Hyg 2007; 77(Suppl 6): 203-218.

5. Marsh VM, Mutemi WM, Muturi J, Haaland A, Watkins WM, Otieno $\mathrm{G}$ et al. Changing home treatment of childhood fevers by training shop keepers in rural Kenya. Trop Med Int Health 1999; 4: 383-389.

6. Salako LA, Brieger WR, Afolabi BM, Umeh RE, Agomo PU. Treatment of childhood fevers and other illnesses in three rural Nigerian communities. $J$ Trop Pedia 2001; 47: 230-238.

7. Brieger WR, Osamor PE, Salami KK, Oladepo O, Otusanya SA. Interactions between patent medicine vendors and customers in urban and rural Nigeria. Health Policy Plan 2004; 19: 177-182

8. Stanback J, Otterness C, Bekiita M, Nakaviza O, Mbonye AK. Injected with controversy: sales and administration of injectable contraceptives in drug shops in Uganda. Int Perspect Sex Reprod Health 2011; 37 24-29.

. Akuse RM, Eseigbe EE, Ahmed A, Brieger WR. Patent medicine sellers: how can they help control childhood malaria? Malar Res Treat 2010; Article ID 470754 7 pages.

10. Federal Ministry of Health/World Health Org zation. Federal Republic of Nigeria Essential Drugs ist, fourth revision 2003. Available from: http://apps. who int/medicinedocs/documents/s16190e/s16190e. pdf. Accessed 2010 May 21.

11. National Drug Authority. Licensing requirements and guidelines for 2011. Available from: http://www. hda.or.ug/docs/NDA\%20Licensing\%20Requirement $\% 20 \& \% 20$ Guidelines $\% 20$ for $\% 202011$.pdf.Accessed 2012 Jan 6

12. Onwujekwe O, Uzochukwu B, Eze S, Obikeze E, Okoli C, Ochonma O. Improving equity in malaria treatment: relationship of socio-economic status with health seeking as well as with perceptions of ease of using the services of different providers for the treatment of malaria in Nigeria. Malar J 2008; 7: 5.

13. Amin AA, Marsh VM, Noor AM, Ochola SA, Snow RW. The use of formal and informal curative services in the management of paediatric fevers in four districts in Kenya. Trop Med Int Health 2003; 8: 1143-1152.

14. Emeka NC. Treatment received by under fives having fever before presenting at the children's outpatient clinic of a tertiary health facility in Owerri, Nigeria. Ann Afri Med 2005; 4: 68-71.

5. National Population Commission (NPC) [Nigeria] and ICF Macro. Nigeria Demographic and Health Survey 2008. Abuja, Nigeria 2009.

16. National Population Commission (NPC) [Nigeria], National Malaria Control Programme (NMCP) [Nigerial, and ICF International Nigeria Malaria Indicator Survey 2010. Abuja, Nigeria: NPC, NMCP, and ICF International.

17. UNICEF. Malaria and children: Progress in intervention coverage. Available from: http://www.unicef org/media/files/WMD_optimized_reprint.pdf.Accessed 2009 Jun 3.

18. Gwatkin DR, Guillot M. The burden of disease among the global poor: current situation, future trends and implications for strategy. Global Forum for Health Research, Geneva 2000.

19. Noor AM, Rage IA, Moonen B, Snow RW. Health service providers in Somalia: their readiness to provide malaria case-management. Malar J 2009; 8: 100 20. Hensen B, Paintain LS, Shretta R, Bruce J, Jones C, Webster J. Taking stock: provider prescribing practices in the presence and absence of ACT stock. Malar J 2011; 10: 218

21. Litrell M, Gatakaa H, Evance I, Poyer S, Njogu J, Solomon $\mathrm{T}$ et al. Monitoring fever treatment behaviour and equitable access to effective medicines in the context of initiatives to improve ACT access: baseline re- 
sults and implications for programming in six African countries. Malar J 2011; 10: 327.

22. Yeung S, Damme WV, Socheat D, White NJ, Mills A. Access to artemisinin combination therapy for malaria in remote areas of Cambodia. Malar J 2008; 7: 96. 23. Federal Republic of Nigeria. Federal Republic of Nigeria official gazette: legal notice on publication of 2006 census final results. Available from: http://placng.org/Legal $\% 20$ Notice $\% 20$ on $\% 20$ Publication $\% 20$ of $\% 202006 \% 20$ Census $\% 20$ Final $\% 20$ Results.pdf. Accessed 2010 Nov 17.

24. The Nigeria: Nigeria, People and Culture. Available from: http://www.the-nigeria.com/2014/05/ list-of-local-government-areas-in-lagos.html\#.VFGWmMkQMhA. Accessed 2014 Oct 30.

25. Varkevisser CM, Pathmanathan I, Brownlee A. Designing and conducting health systems research projects. International Development Centre Ottawa and WHO Geneva. Vol.2:216.

26. Oladepo O, Salami KK, Adeoye BW, Oshiname F, Ofi B, Oladepo $\mathrm{M}$ et al. Malaria treatment and policy in three regions in Nigeria: the role of patent medicine vendors. Available from: http://www.futurehealthsystems.org/publications/WP1\%20final.pdf.Accessed 2008 Jul 12.

27. ACTwatch. The impact of private sector involvement on malaria control interventions in Nigeria: Results from a Baseline Outlet Survey. Available from: http://www.sfhnigeria.org/Impact $\% 20$ of $\% 20$ Private $\% 20$ Sector $\% 20$ Involvement $\% 20$ on $\% 20$ Malaria $\% 20$ Control $\% 20$ Interventions $\% 20 \mathrm{in} \% 20$ Nigeria.pdf. Accessed 2009 Dec 17.

28. Elo S, Kyngäs H. The qualitative content analysis process. J Adv Nurs 2008; 62(1): 107-115.

29. World Health Organization. World malaria report 2011. Switzerland: World Health Organization; 2011.

30. Pharmacists Council of Nigeria Abuja. Approved Patent Medicines List, Third Edition 2003.

31. Pharmacists Council of Nigeria. Guidelines on the Issuance of Patent and Proprietary Medicines Vendor's License. 2003.

32. Okeke TA, Uzochukwu BSC, Okafor HU. An indepth study of patent medicine sellers' perspectives on malaria in a rural Nigerian community. Malar J 2006; 5 : 97. 